\title{
Static and Dynamic Analysis of Vibro Fluidized Bed Dryer using Finite Element Method
}

\author{
Eflita Yohana $^{l *}$, Ismoyo Haryanto ${ }^{l}$, MuhamadAdrian Dwiputra ${ }^{2}$, Yusuf Luqmanul $\mathrm{H}^{2}$ \\ ${ }^{1}$ Department of Mechanical Engineering, Faculty of Engineering, Diponegoro University, Semarang - Indonesia \\ ${ }^{2}$ Undergraduate of Mechanical Engineering Departement, Faculty of Engineering, Diponegoro University, Semarang - Indonesia
}

\begin{abstract}
Vibro Fluidized bed dryer is a widely used tea dryer now. Its function is to stop the enzymatic oxidation process and decrease water content up to $2,8-3,8 \%$. The working principle is to use the vibrations generated by the eccentric motor so that the tea powder that runs on the bed will vibrate. The purpose of this research is to model, static and dynamic of vibro fluidized bed dryer. The analysis was to determine the maximum stress and natural frequency of the vibro fluidized bed dryer to the variation of green tea mass being processed. Using dynamic analysis the obtained first three natural frequencies of the vibro fluidized bed dryer were $5,8876 \mathrm{~Hz}, 9,5267 \mathrm{~Hz}$, and $10,512 \mathrm{~Hz}$. The results showed that at $695 \mathrm{~kg}$ tea mass the natural frequency has the same as the excitation frequency. In this case, the safety factor of the vibro fluidized bed dryer is 27.6. It can be concluded that the maximum capacity of the vibro fluidized bed dryer is $695 \mathrm{~kg}$..
\end{abstract}

Keywords: Vibro Fluidized bed Dryer; Safety factor; Static analysis.

\section{Introduction}

Fluidized Bed Dryer is widely applied in the industrial world ranging from mining, pharmaceutical, food, and others. The fluidized bed dryer is commonly used for drying process in solid objects because it has mass transfer rate and large heat transfer it gives more effectively. The working principle of a fluidized bed dryer is by streaming air into the fluidized bed so that the particles in it can be lifted [1]. Fluidization is the condition of solid particles changing shape into suspension. When air flows go to the fluidized bed dryer, particles lift and move like fluids because the air that flows is larger than the drag force [2]. Under particle fluidization conditions the minimum velocity of fluidization $\left(\mathrm{U}_{\mathrm{mf}}\right)$ is obtained to keep the particles in suspension [3].

Vibro machine Fluidized bed dryer is FBD one of the most widely used types of tea dryers today. The working principle of the vibro fluidized bed dryer is to use the vibrations generated by an eccentric motor so that the tea powder that runs on the bed will vibrate. Vibro fluidized bed dryer serves to stop the enzymatic oxidation process and reduce the water content up to $2.8-3.8 \%$ using heat generated from the heater. Tea powder that is above the bed will be exposed to the flow of hot air from the small hole in the bed. The hot air comes from the heating furnace which is then flowed by the fan and flows through the path under the vibro fluidized bed dryer. water evaporated from the tea powder will be removed by a cyclone to be removed from the vibro fluidized bed dryer [4]. Fluidics a contact process a tea powder with gas or liquid so as to achieve a state of semifluid (fluid-like). The contact between the tea powder and the gas is carried out by means of a gas flowed from the bottom of the porous column so that the tea powder is lifted. Therefore, a fluidized bed drainage flow is required to allow the tea powder in the fluidized bed dryer to be suspended at low airflow. when the airflow velocity increased causing tea powder to move and vibrate in this state is called expansion. When the airflow velocity reaches the minimum speed and the tea powder is suspended for the first time then the tea powder will move away from each other and move which causes the tea powder to have high viscosity. In this state, the thrust force of the moving fluid is balanced by the gravity of the suspended tea powder. This is called the minimum fluidization state and its fluid velocity is called the minimum fluidization velocity $\left(\mathrm{U}_{\mathrm{mf}}\right)[5]$.

The purpose of this research is to model, static and dynamic of vibro fluidized bed dryer. The analysis was to determine the maximum stress and natural frequency of vibro fluidized bed dryer to the variation of green tea mass being processed. hot air flow from the heat exchanger which is flowed by steam coming from the boiler, so that the carbon formed is only in the process of fuel combustion in the boiler

\section{Analysis Method}

The step in this research is, first measure the dimensions of the vibro fluid bed dryer then measure the frequency

\footnotetext{
* Corresponding author: efnan2003@gmail.com
} 
obtained when vibro fluid bed dryer is vibrated. and analyzed using CFD and calculate safety factor in 3 different designs. A system after an interruption is left to vibrate by itself without being influenced by the force from the outside, then the system will oscillate at its natural frequency. At the forced vibration, where the system will vibrate according to the magnitude of the excitation frequency received, then the system will experience resonance. Resonance is a condition that must be avoided when the system is operating, this causes the system to have a large amplitude value and can result in failure of the structure. Mathematically natural frequencies are expressed by [6].

The equation of motion for undamped free vibration system is expressed by:

$$
[M]\{\ddot{\mathrm{x}}\}+[K]\{\mathbf{x}\}=0
$$

where $\ddot{\mathbf{x}}\}$ represents the displacement vector, $\{x\}$ is the acceleration vector. While $[M]$ and $[K]$

representatively the mass matrix and the stiffness matrices of the system. For such systems the natural frequency can be determined by solving the following characteristic equations

$$
[K]-\omega_{n}^{2}[M]=0
$$

Where $\omega_{n}$ which satisfies equation (2) above are the natural frequencies of the system. Static analysis can be done by solving the following equation:

$$
[\mathrm{K}]\{\mathbf{x}\}=\{\mathbf{f}\}
$$

where $\{\mathrm{f}\}$ is an external force vector acting on the system. After the static displacement in Equation (3)

have been determined then the strain $\{\varepsilon\}$ can be calculated. Where stress of the system $[\sigma]$ can be determined using the following stress-strain relations:

$$
[\sigma]=[E]\{\varepsilon\}
$$

In Equation. (4) where $[E]$ is the material stiffness matrix which is the characteristic of the material used. Furthermore, he safety factor of a system can be calculated with equation 3 . Where $\sigma_{y}$ allowable strees of the structural material of fluidized bed dryer.

$$
\mathrm{FS}=\frac{\sigma_{y}}{\sigma}
$$

vibro fluid bed dryer are as follows: Main Framework, Bed, Leaf Spring and Leaf Spring holder.

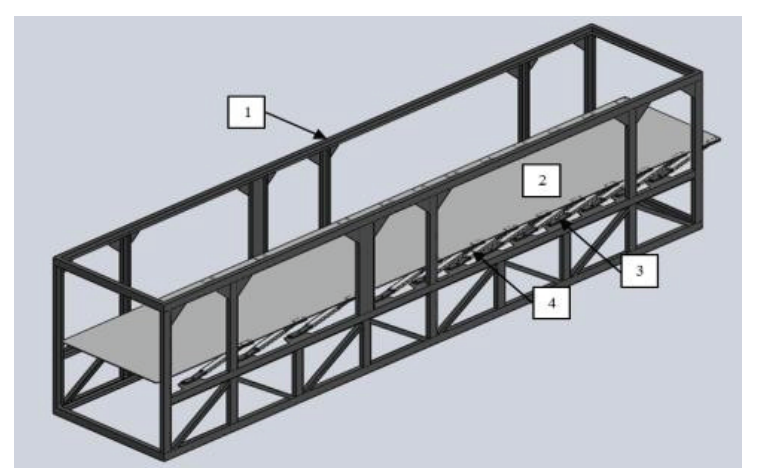

Fig. 1. Geometry of Vibro Fluid Bed Dryer

In this study, the FEM is utilized for analysis static and dynamic of Vibro fluidized bed dryer for this purpose. Meshing on geometry is done using face sizing with element size $195 \mathrm{~mm}$. This meshing generates 95270 total nodes and 38610 total elements. Figure 2 shows the mesh of the vibro fluidized bed dryer.

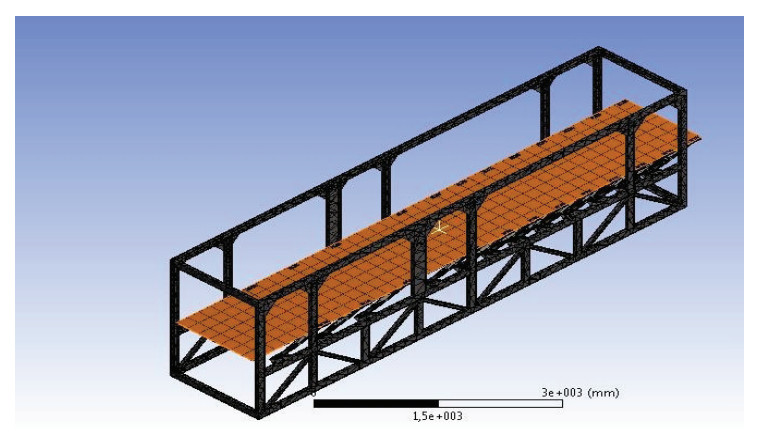

Fig. 2. The Meshing of Vibro Fluid Bed Dryer

\subsection{Modal analysis}

Figures 3, 4 and 5 show the natural frequencies of the first three vibro fluidized bed dryer structures which are $5.8876 \mathrm{~Hz}, 9.5267 \mathrm{~Hz}$, and 10,512 Hz, respectively . As for the static analysis for loading $450 \mathrm{~kg}$ of tea leaves

\section{Results and Discussion}

\subsection{Modeling of Vibro fluid bed dryer}

Figure 1 shows the modeling geometry of the vibro fluid bed dryer used in the simulation process. The parts of the 
obtained von-Mises stress of 5.838 Mpa. Furthermore, the similar analysis is conducted allowing by varying the mass loading of tea. In order to determine the maximum tea mass in the vibro fluidized bed dryer.

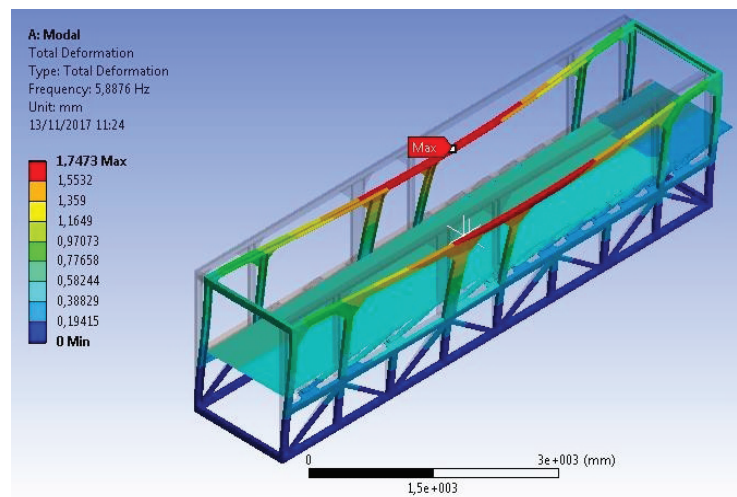

Fig. 3. Mode shape and natural frequency at mode 1

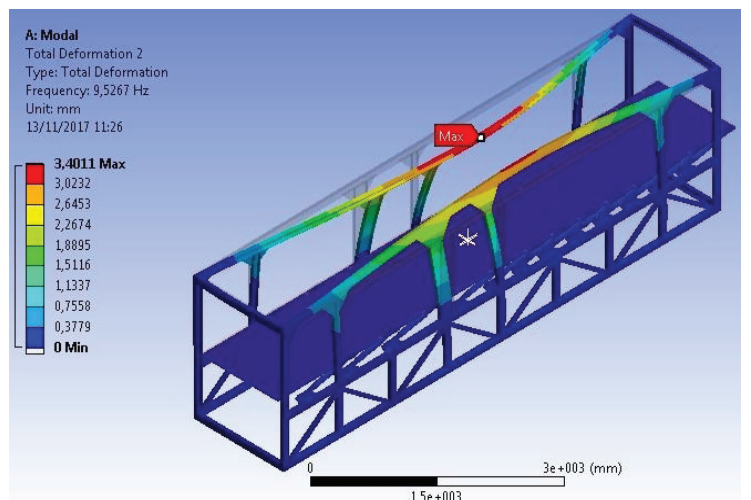

Fig. 4. Mode shape and natural frequency at mode 2

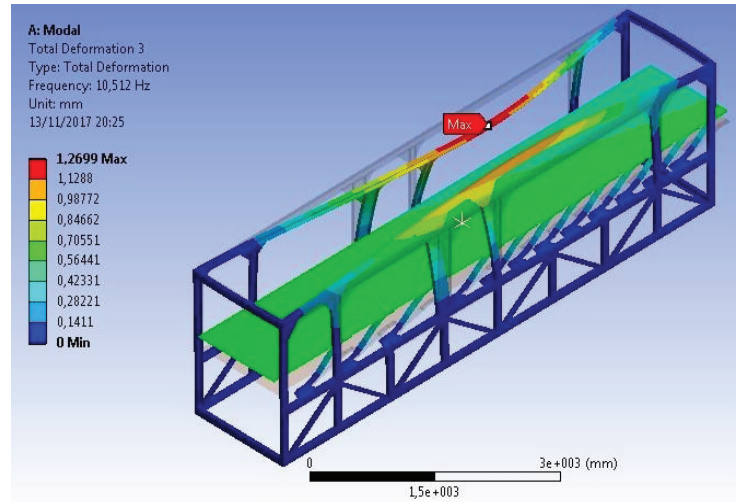

Fig. 5. Mode shape and natural frequency at mode 3

Figure 6 shows the first three of the natural frequency of the fluidized bed dryer as a function of tea mass variation. From the picture is known that the greater the mass of tea. The natural frequency value of the system will be smaller [7]. Because the frequency of excitation of vibro fluidized bed dryer is $5,7545 \mathrm{~Hz}$ then based on the result of capital analysis with variation of loading it can be seen that tea leaf mass should not be equal to $695 \mathrm{~kg}$, because the natural frequency of vibro fluidized bed dryer at loading $695 \mathrm{~kg}$ equal to the frequency of excitation vibro fluidized bed dryer of $5.7545 \mathrm{~Hz}$. It is intended to avoid resonance during the operation of the vibro fluidized bed dryer so that failure of the structure can be avoided.

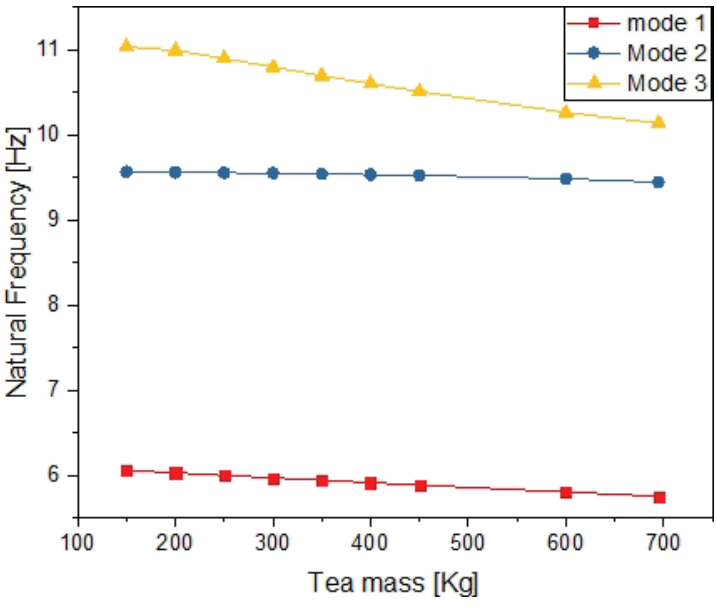

Fig. 6. The Natural frequency with varied loading

\subsection{Static Structural Analysis}

The material used in the vibro fluidized bed dryer is a structural steel material that has properties like are shown in Table 1. The static structural analysis is aimed to determine von-Mises stress on static loading of $450 \mathrm{~kg}$ of tea leaves.

Table 1. Material Properties

\begin{tabular}{|l|c|}
\hline \multicolumn{1}{|c|}{ Properties } & Nilai \\
\hline Density & $7850 \mathrm{~kg} / \mathrm{m}^{3}$ \\
\hline Tensile Yield Strength & $250 \mathrm{Mpa}$ \\
\hline Tensile Ultimate Strength & $460 \mathrm{Mpa}$ \\
\hline
\end{tabular}

Figure 7 known the vibro fluidized bed dryer structure in safe limit because the value of its safety factor is greater than 1 and has the value of safety factor Very large.

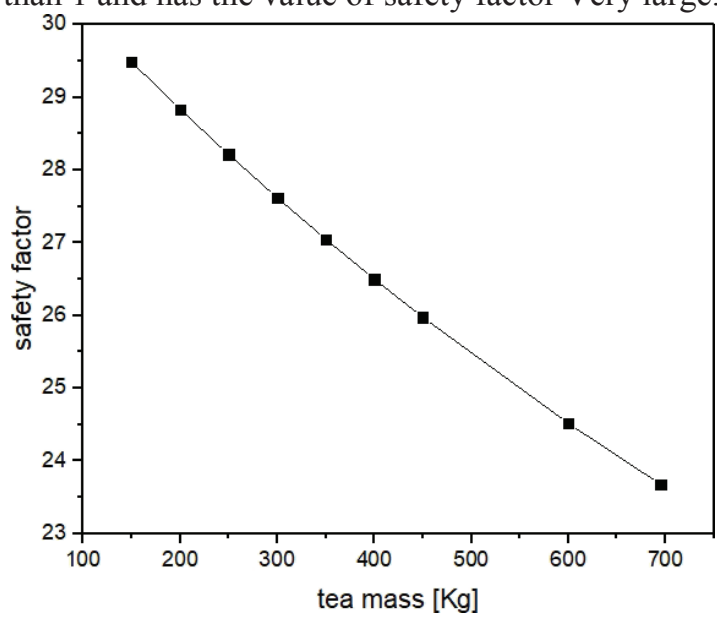

Fig. 7. Safety factor graph with loads varied 


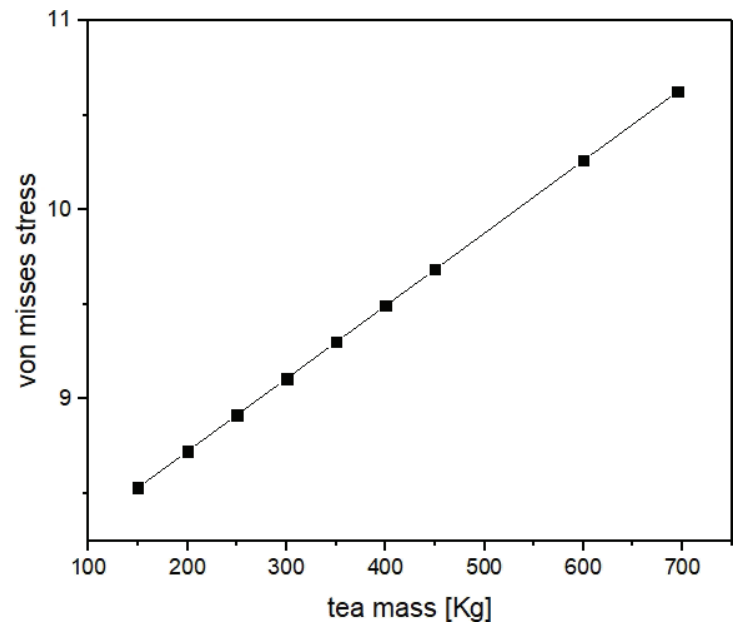

Fig. 8. von-Misses voltage with the varied loading.

Figure 8 shows the von Misses stress with the loading variation. From the picture above is known the greater the mass variation of tea then the von-Misses stress will be greater. From the picture above is known the greater the mass of tea then the value of its safety factor will be smaller.

\section{Conclusion}

From the dynamic analysis of the vibro fluidized bed dryer, it is obtained that the first three natural frequency are $5.8876 \mathrm{~Hz}, 9.5267 \mathrm{~Hz}$, and $10.512 \mathrm{~Hz}$. In this case, the safety factor, on the whole, the loading variation has a value of the safety factor $\mathrm{FS}>>1$ so that the stress occurring in the vibro fluidized bed dryer structure is in the safe category. The larger the tea mass is inserted into the system, the natural frequency in the vibro fluidized bed dryer will be smaller. In the static structural analysis, the greater the mass of tea put into the system, the von- Misses stress experienced by the vibro fluidized bed dryer structure is greater, the highest von-misses velocity at tea mass of $695 \mathrm{~kg}$. hot air flow from the heat exchanger which is flowed by steam coming from the boiler, so that the carbon formed is only in the process of fuel combustion in the boiler

\section{References}

1. Y. belorkar, "Fluidized bed drying of fruit and vegetables," international journal of engineering studies and technical approach, vol. 1, pp. 1-8, (2015).

2. A. latif, "A study of the design of fluidized bed reactors for biomass gasification," university of london, london, (1999).

3. A. de vasconcelo s. douglas p., "minimum and full fluidization velocity for alumina used in the aluminum smelter," international journal of engineering, vol. 3(4), pp. 7-13, (2011).

4. A. Dewi. S, "proses pengeringan bubuk teh pada pengolahan teh hitam CTC," universitas brawijaya malang, lumajang, (2015).

5. W. Widayati, "fenomena dan kecepatan minimum fluidisasi," eksergi, vol. 10(2), pp. 42-46, (2010).

6. W. Thomson, theory of vibration with application, CRC Press, (1996).

7. Rao S.S., mechanichal vibration, Upper saddle river: prentice hall, 2011 